\title{
Quantification of SSVEP Responses Using Multi-Chromatic LED Stimuli: Analysis on Colour, Orientation and Frequency
}

\author{
Surej Mouli, Ramaswamy \\ Palaniappan \\ School of Computing \\ University of Kent \\ surej@ieee.org \\ r.palani@kent.ac.uk
}

\author{
Ian P. Sillitoe \\ School of Engineering \\ University of \\ Wolverhampton \\ Telford \\ United Kingdom
}

\author{
John Q Gan \\ School of Computer Science \\ and Electronic Engineering \\ University of Essex \\ Colchester, United Kingdom
}

\begin{abstract}
Most LED visual stimulators used in steady state visual evoked potential (SSVEP) brain-computer interface (BCI) use single LED sources to elicit SSVEP responses. In this study, we tested the hypothesis that different orientations would have different responses in different participants and aimed to develop a portable LED based stimulus design which consists of a small number of RGB LEDs arranged in a line which can be oriented horizontally or vertically. The colour and frequency of the flicker were controlled by a portable microcontroller platform. The study investigated the performance of the SSVEP from five participants when the LED stimulus was displayed vertically and horizontally for a period of 30 seconds. The frequency range used was from $7 \mathrm{~Hz}$ to $11 \mathrm{~Hz}$ with three primary colours: red, green and blue in both orientations. Furthermore, we also compared the effect of vertical and horizontal orientations using four different frequencies and three colours to test visual fatigue reduction. The results of the analysis using band-pass filtering and Fast Fourier Transform showed that the green horizontal LED stimulus orientation gave the highest response and viewing comfort in all the participants rather than the vertical orientation.
\end{abstract}

\section{Keywords-BCI; EEG; LED Stimulus; Orientation; SSVEP.}

\section{INTRODUCTION}

Brain-computer interface (BCI) is an innovative and widely researched area, which uses nonmuscular communication techniques to convey the brain-wave activity to an external device [1]. Brainwaves are recorded from the scalp using electrodes positioned at different locations non-invasively, processed and utilised for assisting disabled people to perform their basic activities [2-6]. Fig. 1 illustrates the basic data acquisition and information flow to control an external application. Several brain imaging methods such as functional magnetic resonance imaging (fMRI), electroencephalography (EEG), magnetoencephalography (MEG), and nearIR spectroscopy (NIRS) exist and have been adapted in BCI for various applications. Among these imaging techniques, EEG has been popular due to its low cost, portability, and high information transfer rate for real time applications $[3,7,8]$. The commonly used EEG based BCI paradigm which has been very responsive is the steady state visual evoked potential (SSVEP), which is a repetitive sinusoidal like waveform with its frequency synchronised with the frequency of the visual stimulus and recorded from the visual cortex noninvasively [9-14].

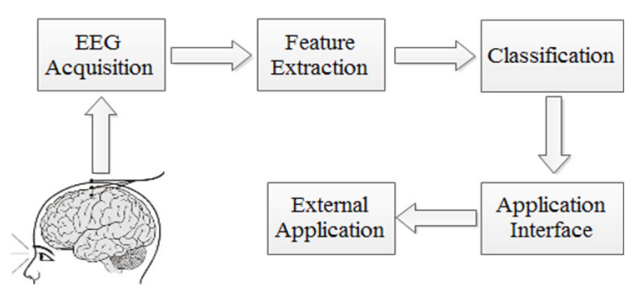

Fig. 1 Basic dataflow in BCI

SSVEP requires a visual stimulus to evoke the potential in the brain and the past studies have shown that the participant responses vary with 
different type of stimuli based on colour, frequency and intensity [14-20]. Even though SSVEP requires minimum number of channels and relatively less user training, it is not always comfortable for the user for prolonged usage [9, 18]. In this study, we have explored the effect of stimulus orientations along with the colour and frequencies of $7,8,9,11 \mathrm{~Hz}$. The frequency 10 $\mathrm{Hz}$ was not used to avoid issues being integer divisor of the $50 \mathrm{~Hz}$ power-line interference. The stimulus orientations used in this study were vertical and horizontal using an array of RGB LEDs arranged at equal distances with each other. These LEDs were driven by microcontroller with pre-programed flicker frequencies for stimulus functionality.

\section{MAterial AND Methods}

\section{A. Experimental Setup}

To investigate the effect of orientations, colour, and frequency on SSVEP, five participants with perfect vision or corrected vision were comfortably seated $60 \mathrm{~cm}$ from the stimulus which was placed at eye level. EEG was recorded using Mobilab ${ }^{+}$from g.tec (http://www.gtec.at) with three electrodes fitted onto an EEG cap. The electrodes were applied with conductive gel to ensure good contact between scalp and the electrodes. The experiment used only minimum number of channels with electrodes positioned at $\mathrm{O}_{z}$ and $\mathrm{F}_{\mathrm{pz}}$ with $\mathrm{A}_{2}$ mastoid as reference. The stimulus was activated with the desired frequency, orientation, and colour to evoke SSVEP for a complete recording cycle of 30 seconds. This process was continued for different orientations, colour and frequencies. For each participant, five trials were conducted for each of the combination from three colours, four different frequencies and two orientations. Five participants in the age group 25-45 (three females, two males), without any previous experience with BCI, participated in this study and were given a short introduction on the study for two minutes before starting the experiment. The experiment received ethical approval prior to any participant involvement.

\section{B. Visual Stimulus}

The visual stimulus used in this study had 12 individual high-bright RGB LEDs, six in a row with rows parallel to each other with a dimension of $170 \mathrm{~mm} \times 55 \mathrm{~mm}$. Each LED is placed at equal distance between each other and in line with each in the adjacent row, to avoid any attention shifts. The visual stimulus activated for green RGB LED in both orientations is shown in Fig. 2. All the LEDs in the visual stimulus were syncronised with the same flickering frequencies for the consistency in evoking the SSVEP. The microcontroller hardware was programmed for ten simultaneous frequency flickers for the visual stimulus and was driven by MOSFETs for constant brightness to maintain uniformity throughout the experiment. The complete hardware was powered by $5 \mathrm{~V}$ DC source through batteries to avoid any interference from the external power supplies. The hardware used for generating the stimulus is shown in Fig. 3. The orientation of the visual stimulus was changed to vertical orientation from its horizontal orientation by turning 90 degrees clockwise for each set of EEG recordings.

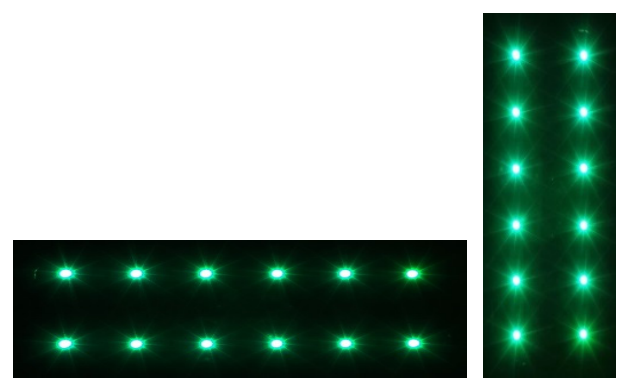

Fig 2. LED stimulus orientations used in this study

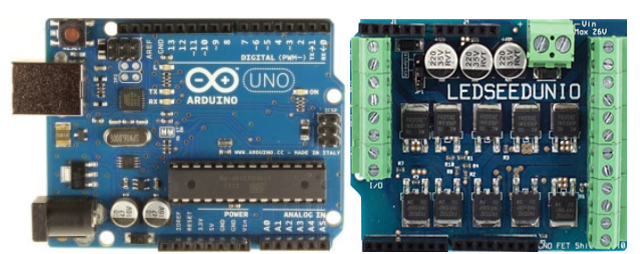

Fig 3. Arduino microcontroller and MOSFET driver 


\section{Data Acquisittion}

Participants with EEG cap fitted with active electrodes and conductive gel applied to the scalp were seated in front of the visual stimulus at eye level during the recording trials. The electrode layout is in line with the standard $10-20$ positioning with one bipolar channel for the entire recording. The recording started with a small demonstration on visualizing the stimulus in the experiment. The flicker frequency, colour, and orientation were selected for each participant for five trials of 30 seconds. After each trial a rest time of one minute was given to the participant to allow the previous responses to subside. The EEG recordings were started with horizontal orientation with green LED at $7 \mathrm{~Hz}$ for 30 seconds with a sampling frequency of $256 \mathrm{~Hz}$ followed by one minute rest time and repeated for all the other frequencies and colours. Each frequency and colour had five trials of 30 seconds duration. This process was repeated for vertical orientation for both colours and frequencies. The complete recorded data set for one participant comprises of three colours, four frequencies, and two orientations. Each participant completed 120 trials, with five trials for each combination from three colours, four frequencies and two orientations, with a total recording time of approximately 120 minutes including the rest time.

\section{Signal Processing}

The EEG data recorded using Matlab was stored as 30 second individual files for further processing. Each 30 second block of data was filtered with a band-pass filter and segmented into one second SSVEP EEG and analysed using Fast Fourier Transform (FFT). The parameters for band-pass elliptical filter are shown in Table I.

TABLE I

FILTER PARAMETERS USED IN THE DATA PROCESSING

\begin{tabular}{|c|c|c|c|c|c|}
\hline $\begin{array}{c}\text { Freq } \\
(\mathrm{Hz})\end{array}$ & Order & $\begin{array}{c}\text { Pass } \\
\text { band } \\
\text { edge } \\
\text { freq }\end{array}$ & $\begin{array}{c}\text { Stop } \\
\text { band } \\
\text { edge } \\
\text { freq }\end{array}$ & $\begin{array}{c}\text { Max } \\
\text { Pass } \\
\text { band } \\
\text { ripple } \\
(\mathrm{dB})\end{array}$ & $\begin{array}{c}\text { Min stop } \\
\text { band } \\
\text { attenuation } \\
(\mathrm{dB})\end{array}$ \\
\hline 7 & 4 & 6,8 & 5,9 & 0.1 & 30 \\
\hline 8 & 4 & 7,9 & 6,10 & 0.1 & 30 \\
\hline 9 & 4 & 8,10 & 7,11 & 0.1 & 30 \\
\hline 11 & 4 & 10,12 & 9,13 & 0.1 & 30 \\
\hline
\end{tabular}

Freq - Frequency
Our previous study based on single RGB LED has explored the significance of colour in SSVEP stimulus and identified green as a prominent colour with the maximum response in SSVEP in all the frequency ranges [21]. In this study an array of LEDs were used to find the significance of colour based on stimulus orientation.

\section{RESULTS AND DISCUSSIONS}

Table II shows the statistical analysis using rank sum to compute the $\mathrm{p}$-values to compare the significance of colour for different frequencies in horizontal and vertical orientation. As mentioned earlier, the study explored three different parameters of visual stimulus influencing the SSVEP amplitude: (a) LED orientation significance, (b) colour significance, and (c) frequency significance.

The filtered signals were processed using FFT to compute the amplitudes, and further statistically compared with rank sum with a significance value (alpha) set to 0.1. Initially, most significant colour for both vertical and horizontal orientation for all frequency ranges were computed and identified as green and results shown in Table II, which indicate that, for all frequency ranges for both vertical and horizontal orientations, green LED stimulus gave the maximal FFT amplitudes in all trials for all participants.

After the identification of prominent colour for SSVEP LED stimulus, the rest of the analysis was based on green LED stimulus. Comparing vertical and horizontal green LED stimulus orientation, the statistical analysis (again using ranksum) identifies horizontal green LED stimulus giving the highest SSVEP values for all the frequency in all participants as shown in Table III.

In the LED stimulus frequency comparison, only horizontal green LED stimulus orientation was statistically analysed as it yielded the highest FFT amplitude for all the participants and the results are shown in Table IV. All four frequencies were compared to identify the highest FFT amplitude and it can be seen that the response from the lowest frequency $7 \mathrm{~Hz}$ was greater than all other frequencies used in the LED visual stimulus. It should be noted that the very small p-values in the tables denotes highly significant difference. 
TABLE II

RANK SUM SigNifiCANCE (P-VALUE) RESUlts COMPARING AMPLITUDES FOR HORIZONTAL AND VERTICAL ORIENTATIONS OF LED STIMULI

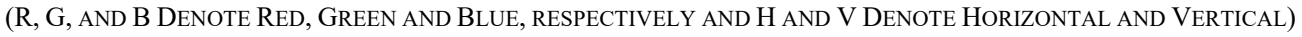

\begin{tabular}{|c|c|c|c|c|c|c|c|c|c|c|}
\hline \multicolumn{11}{|c|}{ Participants } \\
\hline \multirow{2}{*}{$\begin{array}{l}\text { Freq } \\
(\mathrm{Hz})\end{array}$} & \multicolumn{2}{|c|}{$\mathrm{S} 1$} & \multicolumn{2}{|c|}{$\mathrm{S} 2$} & \multicolumn{2}{|c|}{ S3 } & \multicolumn{2}{|c|}{ S4 } & \multicolumn{2}{|c|}{ S5 } \\
\hline & Hyps & Sig & Hyps & Sig & Hyps & Sig & Hyps & Sig & Hyps & Sig \\
\hline $7-\mathrm{H}$ & $\mathrm{G}>\mathrm{R}$ & Yes & $G>R$ & Yes & $G>R$ & Yes & $\mathrm{G}>\mathrm{R}$ & Yes & $G>R$ & Yes \\
\hline $7-\mathrm{H}$ & $\mathrm{B}>\mathrm{R}$ & Yes & $\mathrm{B}>\mathrm{R}$ & Yes & $\mathrm{B}>\mathrm{R}$ & Yes & $\mathrm{B}>\mathrm{R}$ & Yes & $\mathrm{B}>\mathrm{R}$ & Yes \\
\hline $7-\mathrm{H}$ & $G>B$ & Yes & $G>B$ & Yes & $G>B$ & Yes & $G>B$ & Yes & $G>B$ & Yes \\
\hline $7-V$ & $\mathrm{G}>\mathrm{R}$ & Yes & $\mathrm{G}>\mathrm{R}$ & Yes & $\mathrm{G}>\mathrm{R}$ & Yes & $\mathrm{G}>\mathrm{R}$ & Yes & $\mathrm{G}>\mathrm{R}$ & Yes \\
\hline $7-V$ & $\mathrm{R}>\mathrm{B}$ & No & $\mathrm{R}>\mathrm{B}$ & No & $\mathrm{B}>\mathrm{R}$ & Yes & $\mathrm{B}>\mathrm{R}$ & Yes & $\mathrm{B}>\mathrm{R}$ & Yes \\
\hline $7-V$ & $G>B$ & Yes & $\mathrm{G}>\mathrm{B}$ & Yes & $G>B$ & Yes & $\mathrm{G}>\mathrm{B}$ & Yes & $\mathrm{B}>\mathrm{G}$ & No \\
\hline $8-\mathrm{H}$ & $G>R$ & Yes & $\mathrm{G}>\mathrm{R}$ & Yes & $G>R$ & Yes & $\mathrm{G}>\mathrm{R}$ & Yes & $G>R$ & Yes \\
\hline $8-\mathrm{H}$ & $\mathrm{B}>\mathrm{R}$ & Yes & $\mathrm{B}>\mathrm{R}$ & Yes & $\mathrm{B}>\mathrm{R}$ & Yes & $B>R$ & Yes & $\mathrm{B}>\mathrm{R}$ & Yes \\
\hline $8-\mathrm{H}$ & $G>B$ & Yes & $G>B$ & Yes & $G>B$ & Yes & $G>B$ & Yes & $G>B$ & Yes \\
\hline $8-V$ & $\mathrm{G}>\mathrm{R}$ & Yes & $\mathrm{G}>\mathrm{R}$ & Yes & $G>R$ & Yes & $G>R$ & Yes & $G>R$ & Yes \\
\hline $8-V$ & $\mathrm{R}>\mathrm{B}$ & No & $\mathrm{B}>\mathrm{R}$ & Yes & $R>B$ & No & $\mathrm{B}>\mathrm{R}$ & Yes & $\mathrm{B}>\mathrm{R}$ & Yes \\
\hline $8-V$ & $G>B$ & Yes & $G>B$ & Yes & $G>B$ & Yes & $G>B$ & Yes & $G>B$ & Yes \\
\hline $9-\mathrm{H}$ & $\mathrm{G}>\mathrm{R}$ & Yes & $\mathrm{G}>\mathrm{R}$ & Yes & $\mathrm{G}>\mathrm{R}$ & Yes & $\mathrm{G}>\mathrm{R}$ & Yes & $\mathrm{G}>\mathrm{R}$ & Yes \\
\hline $9-\mathrm{H}$ & $\mathrm{R}>\mathrm{B}$ & No & $R>B$ & No & $\mathrm{B}>\mathrm{R}$ & Yes & $B>R$ & Yes & $\mathrm{B}>\mathrm{R}$ & Yes \\
\hline $9-\mathrm{H}$ & $G>B$ & Yes & $G>B$ & Yes & $G>B$ & Yes & $G>B$ & Yes & $G>B$ & Yes \\
\hline $9-V$ & $G>R$ & Yes & $G>R$ & Yes & $G>R$ & Yes & $G>R$ & Yes & $G>R$ & Yes \\
\hline $9-V$ & $\mathrm{R}>\mathrm{B}$ & No & $\mathrm{R}>\mathrm{B}$ & No & $\mathrm{B}>\mathrm{R}$ & Yes & $\mathrm{B}>\mathrm{R}$ & Yes & $\mathrm{B}>\mathrm{R}$ & Yes \\
\hline $9-V$ & $G>B$ & Yes & $G>B$ & Yes & $G>B$ & Yes & $G>B$ & Yes & $G>B$ & Yes \\
\hline $11-\mathrm{H}$ & $G>R$ & Yes & $G>R$ & Yes & $G>R$ & Yes & $\mathrm{G}>\mathrm{R}$ & Yes & $G>R$ & Yes \\
\hline $11-\mathrm{H}$ & $\mathrm{B}>\mathrm{R}$ & Yes & $\mathrm{B}>\mathrm{R}$ & Yes & $\mathrm{B}>\mathrm{R}$ & Yes & $\mathrm{B}>\mathrm{R}$ & Yes & $\mathrm{B}>\mathrm{R}$ & Yes \\
\hline $11-\mathrm{H}$ & $G>B$ & Yes & $G>B$ & Yes & $G>B$ & Yes & $G>B$ & Yes & $G>B$ & Yes \\
\hline $11-V$ & $G>R$ & Yes & $\mathrm{G}>\mathrm{R}$ & Yes & $G>R$ & Yes & $\mathrm{G}>\mathrm{R}$ & Yes & $\mathrm{G}>\mathrm{R}$ & Yes \\
\hline $11-V$ & $\mathrm{R}>\mathrm{B}$ & No & $\mathrm{B}>\mathrm{R}$ & Yes & $\mathrm{B}>\mathrm{R}$ & Yes & $\mathrm{R}>\mathrm{B}$ & No & $\mathrm{B}>\mathrm{R}$ & Yes \\
\hline $11-V$ & $G>B$ & Yes & $G>B$ & Yes & $G>B$ & Yes & $\mathrm{G}>\mathrm{B}$ & Yes & $G>B$ & Yes \\
\hline
\end{tabular}

(Hyps -Hypothesis, Freq -Frequency, Sig- Significance)

TABLE III

RANK SUM SigNifiCANCE (P-VALUE) RESULTS COMPARING AMPLITUDES FOR HORIZONTAL AND VERTICAL ORIENTATIONS OF LED STIMULI (H AND V DENOTE HORIZONTAL AND VERTICAL)

\begin{tabular}{|c|c|c|c|c|c|c|}
\hline \multirow{2}{*}{$\begin{array}{l}\text { Hypothes } \\
\text { is tested } \\
\text { Stimulus } \\
\text { Orientation }\end{array}$} & \multirow{2}{*}{$\begin{array}{c}\text { Freq } \\
\cdot \\
(\mathrm{Hz})\end{array}$} & \multicolumn{5}{|c|}{ Participants } \\
\hline & & $\mathrm{S} 1$ & $\mathrm{~S} 2$ & S3 & S4 & S5 \\
\hline $\mathrm{H}>\mathrm{V}$ & 7 & $\begin{array}{c}7.0 \mathrm{e} \\
-05\end{array}$ & $\begin{array}{c}5.4 \mathrm{e} \\
-28 \\
\end{array}$ & $\begin{array}{c}3.4 \mathrm{e} \\
-05 \\
\end{array}$ & $\begin{array}{c}5.2 \mathrm{e} \\
-05 \\
\end{array}$ & $\begin{array}{c}3.4 \mathrm{e} \\
-09\end{array}$ \\
\hline $\mathrm{H}>\mathrm{V}$ & 8 & $\begin{array}{c}2.0 \mathrm{e} \\
-05\end{array}$ & $\begin{array}{c}1.6 \mathrm{e} \\
-13\end{array}$ & $\begin{array}{c}2.3 e \\
-19\end{array}$ & $\begin{array}{c}1.6 \mathrm{e} \\
-04\end{array}$ & $\begin{array}{c}3.3 e \\
-12\end{array}$ \\
\hline $\mathrm{H}>\mathrm{V}$ & 9 & $\begin{array}{c}1.6 \mathrm{e} \\
-17\end{array}$ & $\begin{array}{c}2.7 \mathrm{e} \\
-05\end{array}$ & $\begin{array}{c}5.7 \mathrm{e} \\
-03\end{array}$ & $\begin{array}{c}1.7 \mathrm{e} \\
-11\end{array}$ & $\begin{array}{c}2.7 \mathrm{e} \\
-06\end{array}$ \\
\hline $\mathrm{H}>\mathrm{V}$ & 11 & $\begin{array}{c}7.4 \mathrm{e} \\
-28\end{array}$ & $\begin{array}{c}6.2 \mathrm{e} \\
-28\end{array}$ & $\begin{array}{c}4.2 \mathrm{e} \\
-22\end{array}$ & $\begin{array}{c}3.4 \mathrm{e} \\
-21\end{array}$ & $\begin{array}{c}1.2 \mathrm{e} \\
-25\end{array}$ \\
\hline
\end{tabular}

SSVEP performance increased with the decrease in stimulus frequency, which also confirms the previous research findings [9, 13, 21]. In terms of qualitative response, all participants felt comfortable with green horizontal LED stimulus rather than vertical LED stimulus orientation. Participants commented that vertical orientation was harder to focus as it seemed to cause strain for eyes resulting in visual fatigue. This also confirms with the previous research in visual orientation, which identifies horizontal orientation is comfortable to visualize and has lesser visual fatigue [22, 23]. All participants recommended green horizontal LED stimulus at higher frequencies though lower frequency gave higher performance as participants felt higher frequencies were easier to gaze. 
TABLE IV

RANK SUM SIGNIFICANCE (P-VALUE) RESULTS COMPARING AMPLITUdes For All THE FREQUENCIES IN HORIZONTAL LED STIMULUS ORIENATION

\begin{tabular}{|c|c|c|c|c|c|}
\hline $\begin{array}{c}\text { Hypothesis } \\
\text { tested (Hz) }\end{array}$ & \multicolumn{5}{|c|}{ Participants } \\
\hline & S1 & S2 & S3 & S4 & S5 \\
\hline $7>8$ & $6.0 \mathrm{e}-$ & $4.0-09$ & $5.7 \mathrm{e}-$ & $7.5 \mathrm{e}-$ & $6.6 \mathrm{e}-$ \\
& 09 & & 09 & 09 & 09 \\
\hline $7>9$ & $2.1 \mathrm{e}-$ & $9.0 \mathrm{e}-$ & $4.0 \mathrm{e}-$ & $4.2 \mathrm{e}-$ & $2.0 \mathrm{e}-$ \\
& 24 & 23 & 23 & 22 & 24 \\
\hline $7>11$ & $2.8 \mathrm{e}-$ & $3.9 \mathrm{e}-$ & $3.3 \mathrm{e}-$ & $7.4 \mathrm{e}-$ & $4.4 \mathrm{e}-$ \\
& 25 & 29 & 24 & 21 & 19 \\
\hline $8>9$ & $4.6 \mathrm{e}-$ & $6.0 \mathrm{e}-$ & $5.6 \mathrm{e}-$ & $5.4 \mathrm{e}-$ & $3.6 \mathrm{e}-$ \\
& 37 & 26 & 29 & 25 & 34 \\
\hline $8>11$ & $5.1 \mathrm{e}-$ & $3.2 \mathrm{e}-$ & $3.5 \mathrm{e}-$ & $4.6 \mathrm{e}-$ & $3.1 \mathrm{e}-$ \\
& 34 & 21 & 38 & 28 & 25 \\
\hline $9>11$ & $9.3 \mathrm{e}-$ & $8.4 \mathrm{e}-$ & $7.4 \mathrm{e}-$ & $8.4 \mathrm{e}-$ & $7.1 \mathrm{e}-$ \\
& 06 & 07 & 08 & 09 & 25 \\
\hline
\end{tabular}

\section{CONCLUSION}

In this study, we have investigated how horizontal and vertical LED stimuli affect the SSVEP amplitudes. The results in this study identified that green horizontal LED stimulus produces the maximum responses. The participants also stated that this setup was easier to concentrate as well and prolonged usage did not increase the strain for their eyes. As for the frequency, the lowest frequency, 7 $\mathrm{Hz}$, resulted in the highest SSVEP amplitude for all colour ranges even though the participants preferred higher frequencies as these were easier to gaze continuously.

This study concludes that the orientation of the stimulus has significant effects on SSVEP amplitudes as well as user comfort level when used for prolonged period and horizontal orientation of LEDs is easier to concentrate. Since this was a pilot study the number of participants was limited to five. In future studies more participants from different age groups could be included. This study can be used in BCI with multiple LED stimuli in horizontal orientation at different frequencies for various applications. Further work may include the study of horizontal pattern influences in SSVEP to improve the amplitude as well as quantification of the visual fatigue reduction.

\section{REFERENCES}

[1] J. R. Wolpaw, N. Birbaumer, D. J. McFarland, G. Pfurtscheller, and T. M. Vaughan, "Brain-computer interfaces for communication and control," Clinical Neurophysiology, vol. 113, no. 6, pp. 767-791, 2002.

[2] R. Prueckl and C. Guger, "Controlling a robot with a braincomputer interface based on steady state visual evoked potentials," Proceedings of International Joint Conference on Neural Networks, pp. 1-5, 2010.

[3] G. Pires, U. Nunes, and M. Castelo-Branco, "Evaluation of brain-computer interfaces in accessing computer and other devices by people with severe motor impairments," Procedia Computer Science, vol. 14, pp. 283-292, 2012.

[4] G. R. Muller-Putz and G. Pfurtscheller, "Control of an electrical prosthesis with an SSVEP-based BCI," IEEE Transactions on Biomedical Engineering, vol. 55, no. 1, pp. 361-364, 2008.

[5] P. F. Diez, S. M. Torres Müller, V. A. Mut, E. Laciar, E. Avila, T. F. Bastos-Filho, and M. Sarcinelli-Filho, "Commanding a robotic wheelchair with a high-frequency steady-state visual evoked potential based brain-computer interface," Medical Engineering \& Physics, vol. 35, no. 8, pp. 1155-1164, 2013.

[6] D. De Massari, T. Matuz, A. Furdea, C. A. Ruf, S. Halder, and N. Birbaumer, "Brain-computer interface and semantic classical conditioning of communication in paralysis," Biological Psychology, vol. 92, no. 2, pp. 267274, 2013

[7] Y. M. Chi, W. Yu-Te, W. Yijun, C. Maier, J. Tzyy-Ping, and G. Cauwenberghs, "Dry and noncontact EEG sensors for mobile brain-computer interfaces," IEEE Transactions on Neural Systems and Rehabilitation Engineering, vol. 20, no. 2, pp. 228-235, 2012.

[8] Z. Wu, L. Kang, F. Shen, and B. Fang, "The closed-loop human-computer interface: active information acquisition for vision-brain-hand to computer (VBH-C) interaction based on force tablet," Proceedings on First International Conference on Neural Interface and Control, pp. 1-5, 2005.

[9] I. Volosyak, D. Valbuena, T. Luth, T. Malechka, and A. Graser, "BCI demographics II: How many (and what kinds of) people can use a high-frequency SSVEP BCI?" IEEE Transactions on Neural Systems and Rehabilitation Engineering, vol. 19, no. 3, pp. 232-239, 2011.

[10] C. S. Herrmann, "Human EEG responses to $1-100 \mathrm{~Hz}$ flicker: resonance phenomena in visual cortex and their potential correlation to cognitive phenomena," Exp Brain Res, vol. 137, no. 3-4, pp. 346-53, 2001.

[11] M. A. Pastor, J. Artieda, J. Arbizu, M. Valencia, and J. C. Masdeu, "Human cerebral activation during steady-state visual-evoked responses," J Neurosci, vol. 23, no. 37, pp. 11621-7, 2003.

[12] H. J. Hwang, J. H. Lim, Y. J. Jung, H. Choi, S. W. Lee, and C. H. Im, "Development of an SSVEP-based BCI spelling system adopting a QWERTY-style LED keyboard," $J$ Neurosci Methods, vol. 208, no. 1, pp. 59-65, 2012.

[13] S. N. Resalat, V. Saba, F. Afdideh, and A. Heidarnejad, "High-speed SSVEP-based BCI: Study of various frequency pairs and inter-sources distances," Proceedings of IEEE-EMBS International Conference on In Biomedical and Health Informatics (BHI), pp. 220-223, 2012.

[14] S. Walter, C. Quigley, S. K. Andersen, and M. M. Mueller, "Effects of overt and covert attention on the steady-state visual evoked potential," Neuroscience Letters, vol. 519, no. 1, pp. 37-41, 2012.

[15] M. A. Lopez-Gordo, A. Prieto, F. Pelayo, and C. Morillas, "Customized stimulation enhances performance of independent binary SSVEP-BCIs," Clinical Neurophysiology, vol. 122, no. 1, pp. 128-133, 2011.

[16] S. Nishifuji, T. Kuroda, and S. Tanaka, "EEG changes associated with mental focusing to flicker stimuli under eyes closed condition for SSVEP-based BCI," 
Proceedings of SICE Annual Conference, pp. 475-480, 2012.

[17] L. Po-Lei, Y. Chia-Lung, J. Y. S. Cheng, Y. Chia-Yen, and L. Gong-Yau, "An SSVEP-based BCI using high dutycycle visual flicker,", IEEE Transactions on Biomedical Engineering, vol. 58, no. 12, pp. 3350-3359, 2011.

[18] S. N. Resalat, S. K. Setarehdan, F. Afdideh, and A. Heidarnejad, "Appropriate twinkling frequency and intersources distance selection in SSVEP-based HCI systems," Proceedings of IEEE International Conference on Signal and Image Processing Applications (ICSIPA), 2011, pp. 12-15.

[19] Y. Wang, Y. T. Wang, and T. P. Jung, "Visual stimulus design for high-rate SSVEP BCI," Electronics Letters, vol. 46, no. 15, pp. 1057-1058, 2010.

[20] Z. Wu, Y. Lai, Y. Xia, D. Wu, and D. Yao, "Stimulator selection in SSVEP-based BCI," Medical Engineering \& Physics, vol. 30, no. 8, pp. 1079-1088, 2008.

[21] S. Mouli, R. Palaniappan, I. P. Sillitoe, and J. Q. Gan, "Performance analysis of multi-frequency SSVEP-BCI using clear and frosted colour LED stimuli," Proceedings of IEEE $13^{\text {th }}$ International Conference on Bioinformatics and Bioengineering (BIBE), pp 1-4, 2013.

[22] L. Ahnate, and S. Scott, "Reexamining visual orientation anisotropies: A bias towards simple horizontal stimuli on temporal order judgments," In N. Miyake, D. Peebles, \& R. P. Cooper (Eds.), Proceedings of the 34th Annual Conference of the Cognitive Science Society, pp. 19121917, 2012.

[23] J. C. Read, and B. G. Cumming, "Understanding the cortical specialization for horizontal disparity," Neural computation, vol. 16, no. 10, pp. 1983-2020, 2004. 